\title{
Malonic aciduria
}

INSERM

\section{Source}

INSERM. (1999). Orphanet: an online rare disease and orphan drug data base. Malonic aciduria. ORPHA:943

Malonic aciduria is a metabolic disorder caused by deficiency of malonyl-CoA decarboxylase (MCD). 